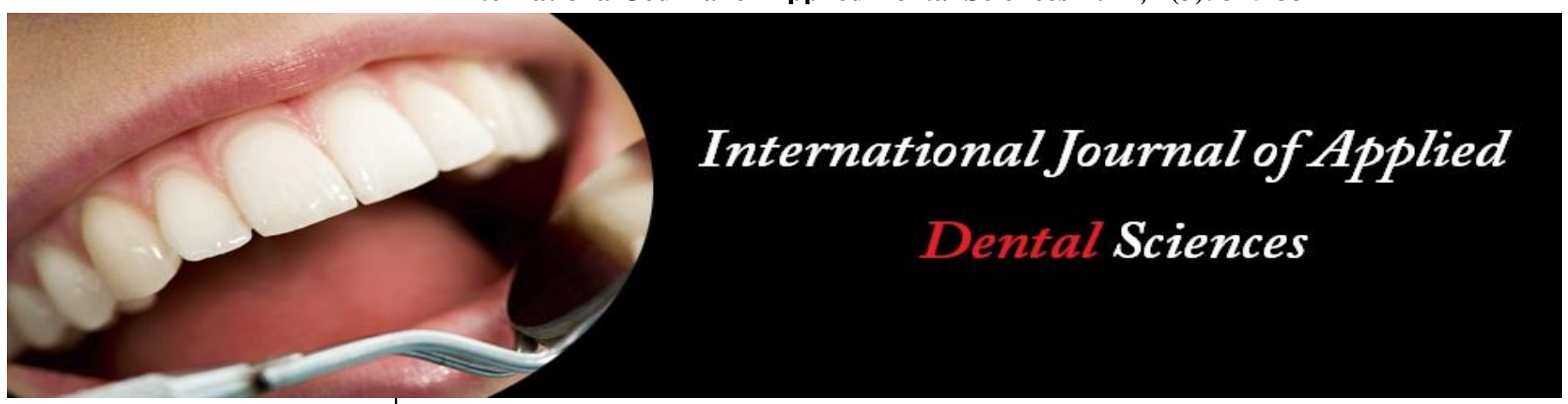

ISSN Print: 2394-7489

ISSN Online: 2394-7497

IJADS 2021; 7(3): 325-331

(C) 2021 IJADS

www.oraljournal.com

Received: 22-05-2021

Accepted: 25-06-2021

Dr. Vibha Hegde

Professor and HOD

Dept. of Conservative Dentistry and Endodontics, YMT Dental

College and Hospital,

Maharashtra, India

Dr. Amber Ansari

Postgraduate, Dept. of

Conservative Dentistry and

Endodontics, YMT Dental

College and Hospital,

Maharashtra, India

Dr. Nikita Singh

Postgraduate, Dept. of

Conservative Dentistry and

Endodontics, YMT Dental

College and Hospital,

Maharashtra, India
Corresponding Author:

Dr. Vibha Hegde

Professor and HOD

Dept. of Conservative Dentistry and Endodontics, YMT Dental

College and Hospital,

Maharashtra, India

\section{Comparative Evaluation of the Microtensile Bond strength of composite resin to Bleached Enamel: An In vitro Experimental Study}

\author{
Dr. Vibha Hegde, Dr. Amber Ansari and Dr. Nikita Singh
}

DOI: https://doi.org/10.22271/oral.2021.v7.i3e.1320

\section{Abstract}

Aim: Comparative evaluation of the effectiveness of $10 \%$ sodium ascorbate solution and delayed treatment on the microtensile bond strength of nanocomposite to bleached enamel using two step etch and rinse and self-etch adhesive technique.

Materials and methods: Forty extracted human maxillary central incisors were decoronated, and the crown portion was embedded in acrylic resin with the buccal surface facing upwards. The specimens were randomly allocated to four groups which were further sub-divided into two groups according to the adhesion protocol.

Group I- (control group): No bleaching followed by restoration.

Group II: Bleaching followed by immediate restoration.

Group III: Bleaching followed by surface treatment with $10 \%$ sodium ascorbate for 30 mins followed by restoration.

Group IV: Bleaching followed by restoration after 14 days.

Result: Statistically significant differences were found between microtensile bond strength of bleached enamel with surface treatment with $10 \%$ sodium ascorbate solution and no surface treatment group.

Conclusion: Bleaching followed by surface treatment with $10 \%$ sodium ascorbate for 30 mins followed by restoration showed similar strength as compared the control group.

Keywords: Sodium ascorbate, Bleaching, Microtensile bond strength

\section{Introduction}

Smile is considered as a person's ability to express a range of emotions with the structure and movement of the teeth and lips ${ }^{[1]}$. One of the most common clinical issues related to aesthetics is pigmentation of dental structures. Mankind has always tried to improve the facial features, for looking appealing, since the appearance and alignment of teeth influence the personality of a person. With increasing understanding of aesthetic dentistry, bleaching has become a very common procedure ${ }^{[2]}$.

Tooth whitening systems was first introduced by Haywood and Heymann in 1989. Vital tooth bleaching can be accomplished by carbamide or hydrogen peroxide (HP) bleaching agents at different concentrations in esthetic Dentistry ${ }^{[3]}$. As vital and non-vital bleaching has become widely known, clinician should have a thorough knowledge of the outcome of the bleaching treatment and their interactions with further dental procedures, especially in terms of adhesive restorations. There have been reports of a relationship between bleaching agents and the strength with which composite materials bond to enamel and dentin. ${ }^{[4]}$ Tooth sensitivity and gingival irritation, may occur following whitening procedures performed at the clinic or in the office, although it is regarded as a safe option.

It has been proposed that residual oxygen from the bleaching process remains within the tooth structure for up to 2 weeks and is believed to interfere with polymerization of the dentin adhesives ${ }^{[5]}$. Although the immediate negative effect of bleaching on bond strength have been known through multiple studies, it is reported that waiting for at least 7 days, dentin bond strength values return to baseline ${ }^{[6-8]}$. Although bleaching effects on dentin aren't long-term, antioxidants like sodium ascorbate is used to counteract the adverse effects of bleaching to 
permit immediate placement of a restoration ${ }^{[9-11]}$.

More than 5 decades ago, Buonocore introduced the concept of bonding to tooth structure when he introduced bonding resin to acid-etched enamel. Since then, the acid-etch technique has become the gold standard procedure for restoration with resin composites to enamel. The introduction of self-etching adhesives eliminated the utilization of a separate acid-etching step and significantly reduced postoperative sensitivity related to composite restorations due to incorporation of the smear layer into the bonding interface. Sano and others permitted measurement of the tensile strength of small specimens $(0.5 \mathrm{~mm} 2$ in cross section) by measuring the microtensile bond strength ( $\mu$ TBS) test ${ }^{[12]}$.

Thus, the aim of this study was to comparatively evaluate the effectiveness of $10 \%$ sodium ascorbate solution and delayed treatment on the microtensile bond strength of nanocomposite to bleached enamel using total etch and self-etch adhesive technique.

\section{Methodology}

Forty extracted maxillary central incisors were selected for the study. The teeth were screened radiographically to include the teeth without caries in the crown. The external surfaces were scaled with ultrasonic instruments to remove any soft tissue or calculus. The specimens were decoronated (Fig.1) to obtain the crown portion of the tooth and was embedded in acrylic resin with the buccal surface of the specimen facing upwards (Fig.2). The specimens were then divided into four groups of 10 teeth each according to the treatment protocol i.e.

Group I- (control group): No bleaching followed by restoration.

Group II: Bleaching followed by immediate restoration.

Group III: Bleaching followed by surface treatment with $10 \%$ sodium ascorbate for 30 mins followed by restoration.

Group IV: Bleaching followed by restoration after 14 days.

The specimens were further sub-divided into two groups according to the adhesion protocol for composite restoration which was total etch and self-etch technique.

\subsection{Bleaching Procedure}

Bleaching was done on the buccal surface of incisors with $35 \%$ hydrogen peroxide according to the manufacturer's instructions, a $1 \mathrm{~mm}$ thick layer was applied for $20 \mathrm{~min}$ on the enamel surfaces of all groups (Fig.3), except for Group I. After this period, the gel was removed, and a new layer of gel was applied for an additional $20 \mathrm{~min}$. Next, the specimens were washed and immersed in distilled water for $5 \mathrm{~min}$.

\subsection{Application of Antioxidant}

$10 \%$ sodium ascorbate solution was applied with a microbrush on the enamel surfaces of the previously bleached Group III specimens (Fig. 4). The application of sodium ascorbate was performed for 30 mins according to the study by Tostes et al. ${ }^{[14]}$

\subsection{Restorative Procedure}

5 specimens from each of the four group were etched with $37 \%$ phosphoric acid for 15 seconds (Fig. 5), washed with saline and air dried. Bonding agent was applied on the tooth surface and cured for 20 seconds (Fig.6); the other 5 specimens were bonded using the self-etch adhesive (Fig.7). After that the nanocomposite resin was placed in three increments of $2 \mathrm{~mm}$ each on the buccal surface and light cured using LED light curing unit for 20 seconds each (Fig.8).

\subsection{Microtensile Bond Strength Testing}

The prepared specimens were then sectioned using a micromotor attached to a diamond disk with copious saline irrigation (Fig.9) to obtain beam shaped samples of $2 \mathrm{~mm}$ thickness made from the mesial to the distal surface and from the cervical to the incisal surface containing enamel, dentin and the composite resin, obtaining an average of 5 sticks from each specimen (Fig.10). Thus, each group had a sample size of 25 samples each. The beam specimens were subjected to tensile forces at a crosshead speed of $1 \mathrm{~mm} / \mathrm{min}$ (Fig.11). Microtensile bond strength (MPa) was calculated based on the force at debond in Newtons (Fig.12) divided by the beam interface cross-sectional area ( $\mathrm{mm} 2)$.

\section{Statistical Analysis}

Descriptive statistics were expressed as means and standard deviation. The intergroup comparative evaluation of the microtensile bond strength of bleached enamel to composite resin using two adhesive systems was analyzed using Unpaired t test. Within group comparison was done using One way ANOVA test followed by post hoc Bonferroni test. In the above tests, $\mathrm{p}$ value of less than or equal to 0.05 was considered to be statistically significant. All analyses were performed using SPSS software version 20.

\section{Results}

The mean and standard deviation of the microtensile bond strength of composite resin to bleached enamel are presented in Table no 1 and Table no 2. Bleaching followed by immediate composite resin restoration (group 2) showed the lowest microtensile bond of $16.7 \mathrm{Mpa}$ strength. The microtensile bond strength of bleaching followed by $10 \%$ sodium ascorbate solution treatment (group 3) of $26.94 \mathrm{MPa}$ and bleaching followed by restoration after 14 days (group 4) of $25.54 \mathrm{MPa}$ was comparable to that of no bleaching followed by restoration (group 1: positive control) of 30.64 $\mathrm{MPa}$.

\section{Discussion}

Since the inception of the first bleaching treatment methods (Haywood and Heymann, 1989), various bleaching systems have been introduced using $10 \%, 15-16 \%$ or $20-22 \%$ Carbamide peroxide, $35 \%$ hydrogen peroxide as the active bleaching agent ${ }^{[13]}$. Matis et al. (1998) stated that bleaching of vital teeth notably has been shown to be a safe and acceptable procedure for removing stains. The reason being that bleaching is a economic procedure for patients who do not easily accept additional esthetic dental procedures. Christensen et al. 1997 also proposed that, after bleaching the patients often show a greater interest in veneers, closure of diastemas and other esthetic procedures.

Although bleaching has proved to be meritorious in different ways, de Lima et al. (2009) and Dias Ribeiro et al. (2009), in their studies stated that it may present certain undesirable side effects such as pulp toxicity, microleakage, external root resorption, changes in the structure of tooth, decrease in microhardness as well as the bond strength reduction of composite resin to tooth structures. After the bleaching treatment, patients usually desire for a more esthetic procedures such as laminate veneers or composite resin restoration for restoring deficiencies ${ }^{[14]}$. The residual oxygen remaining on tooth surfaces after bleaching as stated by Rueggeberg and Margeson, (1990) can interfere with adhesion of the adhesive system applied for restorative procedures. All in all, the decrease in bond strength may 
evoke several other factors which include an increase in microleakage, changes in fracture resistance as given by Khoroushi and Fardashtaki, (2009) ${ }^{[15]}$ and increase in tooth surface porosity stated by Titley et al. $(1991)^{[16]}$.

However, Titley et al. (1991), showed that the bleaching process may result in residual peroxide, which has an immediate adverse effect on bond strength of adhesive restorations to tooth structures. In a systematic review by Feiz A et al. (2017) ${ }^{[17]}$, the results obtained showed that the use of antioxidant agents, regardless of their type, form, concentration and duration of application, can improve the shear bond strength after bleaching. However, to ensure an adequate bond strength using two different bonding strategies i.e total etch technique and self-etch technique can be evaluated by testing the microtensile bond strength.

Therefore, the present study aims at comparatively evaluating the effectiveness of $10 \%$ sodium ascorbate solution and delayed treatment on the microtensile bond strength of nanocomposite to bleached enamel using total etch and selfetch adhesive technique.

Consequently, different treatment methods to overcome the compromised bond strength have been suggested for solving clinical problems related to post-bleaching side effects. As early as 1991 kalili et al, ${ }^{[18]}$ suggested use of alcohol for treating bleached enamel. Later, Barghi and Godwin (1994) ${ }^{\text {[19] }}$ proposed removal of the superficial enamel layer. In this context, Sung et al. (1999) ${ }^{[20]}$ have similarly pointed to the use of adhesives which contain organic solvents. However, Kaya and Turkun (2003) [8] Torres et al. (2006) [21] have offered other techniques for solving the problem including the application of antioxidant agents such as sodium ascorbate, ascorbic acid, catalase, acetone, butylated hydroxyanisole, and alpha-tocopherol via the 2,2-diphenyl-1-picryl hydrazylhydrate free radical method or certain mouthrinses with an antioxidant activity like sodium fluoride, chlorhexidine and essential oils as well as photopolymerization ${ }^{[22]}$.

Also, one of the methods to mitigate the reduced bond strength as given by Cavalli et al. (2005) ${ }^{[23]}$ is to delay any restorative procedure for a certain amount of. Since it has been shown that the decrease in bond strength is temporary, clinicians usually postpone bonding procedures for a week after bleaching procedures. This waiting period can differ from 1 week to 3 weeks according to Cavalli et al. (2005). ${ }^{[23]}$ Also, in the present study the microtensile bond strength of Group 4 (bleaching followed by restoration after 2 weeks) of 25.45 $\mathrm{MPa}$ showed comparable bond strength to the positive control Group 1(no bleaching followed by restoration) of $30.64 \mathrm{MPa}$. These results were in accordance with study by van der Vyver et al. (1997) ${ }^{[24]}$, Unlu et al. (2008) ${ }^{[25]}$ and Freire et al. (2011) ${ }^{[26]}$.

It has been demonstrated by Kaya et al. (2008) ${ }^{[27]}$, and Freire et al. (2011) ${ }^{[26]}$ that the decrease in adhesive bond strength of resin to enamel and dentin after bleaching process depends on concentration and application time of bleaching materials. Reduction in bond strength caused by hydrogen peroxide can be reversed with sodium ascorbate as an antioxidant as stated by Lai et al. (2001) ${ }^{[28]}$. Türkün and Kaya (2004) ${ }^{[8]}$ in their study showed that use of sodium ascorbate even for $10 \mathrm{~min}$ is enough to reverse the reduced bond strength, but in a study by Kaya et al. (2008) ${ }^{[27]}$ claimed that the antioxidant should be applied for at least 30 minutes for maximum effectiveness and an increase in the application time of sodium ascorbate (SA) can lead to a greater increase in microtensile bond strength.

The microtensile bond strength after $35 \%$ hydrogen peroxide bleaching of tooth followed by surface treatment with $10 \%$ sodium ascorbate solution and then restoration in the present study showed $26.94 \mathrm{MPa}$ in the present study. There was no statistically significant difference seen between group 4 and group 1 . These results were in accordance with study by Kaya et al. (2008) ${ }^{[27]}$, Freire et al. (2011) ${ }^{[26], ~ K i m y a i ~ e t ~ a l . ~(2010) ~}$ [29], Turkun et al. (2009) [30], Dabas et al. (2011) [31], Lima et al. (2011) ${ }^{[32]}$ and Thapa et al. (2013) ${ }^{[33]}$. These results were attributed to the neutralizing effect of sodium ascorbate on the residual oxygen on the tooth. Residual oxygen released from the bleaching material at the enamel surface has been considered to be the main reason for decreased bond strength, which inhibits resin polymerization or interferes with the resin infiltration into the etched enamel. However, study by $\mathrm{M}$. Stephen Harrison et al. (2019) [37] showed that alpha tocopherol was a better antioxidant as compared to sodium ascorbate. The reason being antioxidants sodium ascorbate when used for clinically extended periods, the reversal of dentin bond strength reductions was not found successful.

Additionally, biological alterations happening in bleaching processes can result in a considerable reduction in microtensile bond strength which might be due to the modifications occurring in enamel structure, increased porosity manifested by loss of enamel prisms, and an overetched appearance. The use of the adhesive system also has a significant effect on the bond strength of resin to bleached enamel and dentin. In the present study, all the four major groups were subdivided into 2 sub-groups according to the bonding procedure using two step etch and rinse or one step self-etching adhesive. The results of the etch and rinse group for all the four groups was statistically higher than self-etch group. These results were in accordance with the study by Khoroushi and Aghelinejad, (2011) ${ }^{[15]}$. However, studies by Abraham et al. (2013) ${ }^{[34]}$, Ozoe et al. (2012) ${ }^{[35]}$ and Yoon et al. (2014) ${ }^{[36]}$ demonstrated that regardless of the type of adhesive system used, application of antioxidants before restorative procedures reverses the negative effect of bleaching on the bond strength.

Also, it is important to mention that the present values are measured under ideal laboratory conditions, i.e., higher irradiance, longer curing time and direct contact of the light curing tip on the sample, which may not necessarily be expected in general practice. Both intrinsic and extrinsic factors are known to affect the physical properties of the resin based composites. The shortcoming of the present study could be that under in-vivo conditions various variables such as, thermo-chemical factors, variations of magnitude, speed and directions of masticatory forces that are peculiar to individuals' oral environment, occlusion, wear-ability, long term durability affect resin based restorations. 
Table 1: Intragroup comparison of the microtensile bond strength of bleached enamel to composite resin using two adhesive systems.

\begin{tabular}{|c|c|c|c|c|}
\hline & Group 1 (Mean \pm SD) & Group 2 (Mean \pm SD) & Group 3 (Mean \pm SD) & Group 4 (Mean \pm SD) \\
\hline Etch and rinse & $30.26 \pm 3.43^{\mathrm{a}}$ & $16.70 \pm 2.00^{\mathrm{b}}$ & $26.94 \pm 2.90^{\mathrm{a}}$ & $25.45 \pm 4.96^{\mathrm{a}}$ \\
\hline P value (One Way ANOVA test) & \multicolumn{5}{|c|}{$<0.00 *^{*}$} \\
\hline & Group 1 (Mean \pm SD) & Group 2 (Mean \pm SD) & Group 3 (Mean \pm SD) & Group 4 (Mean \pm SD) \\
\hline Self-etch & $20.59 \pm 2.39^{\mathrm{a}}$ & $9.12 \pm 1.21^{\mathrm{b}}$ & $19.50 \pm 3.12^{\mathrm{a}}$ & $18.74 \pm 3.58^{\mathrm{a}}$ \\
\hline P value (One Way ANOVA test) & \multicolumn{5}{|c}{$<0.001^{*}$} \\
\hline
\end{tabular}

$\dagger$ Post hoc Bonferroni test: Similar superscript letters denote no statistical significant difference $(\mathrm{p}>0.05)$ and dissimilar letters exhibit a statistically significant difference $(\mathrm{p} \leq 0.05)$

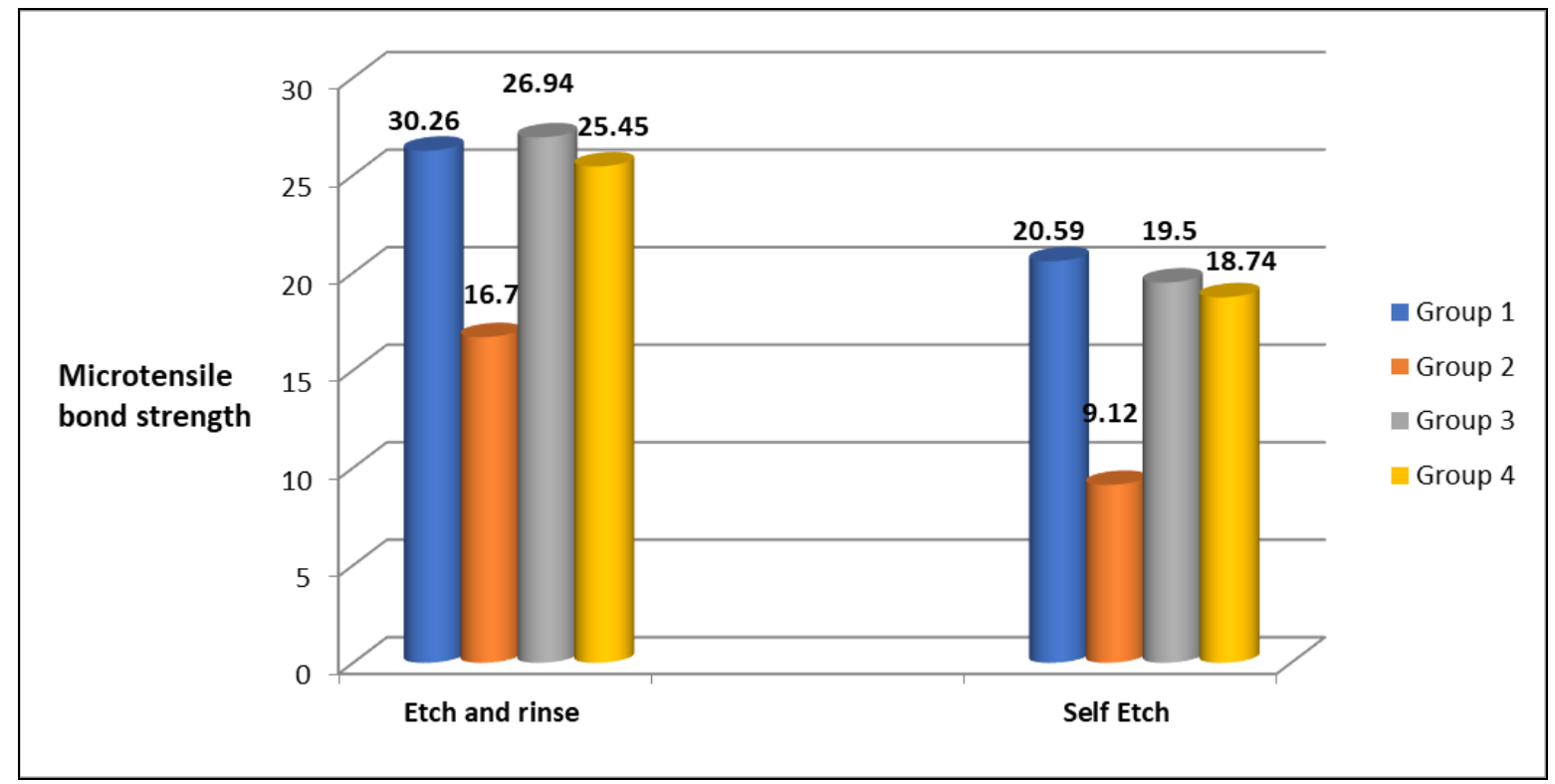

Fig 1: Intragroup comparison of the microtensile bond strength of bleached enamel to composite resin using two adhesive systems.

Table 2: Intergroup comparison of the microtensile bond strength of bleached enamel to composite resin using two adhesive systems.

\begin{tabular}{|c|c|c|c|}
\hline & Etch and rinse & Self-etch & P Value (Unpaired t test) \\
\hline Group 1 & $30.26 \pm 3.43$ & $20.59 \pm 2.39$ & $<0.001^{*}$ \\
\hline Group 2 & $16.70 \pm 2.00$ & $9.12 \pm 1.21$ & $<0.001^{*}$ \\
\hline Group 3 & $26.94 \pm 2.90$ & $19.50 \pm 3.12$ & $<0.001^{*}$ \\
\hline Group 4 & $25.45 \pm 4.96$ & $18.74 \pm 3.58$ & $<0.001^{*}$ \\
\hline
\end{tabular}

$\mathrm{P} \leq 0.05$ is statistically significant

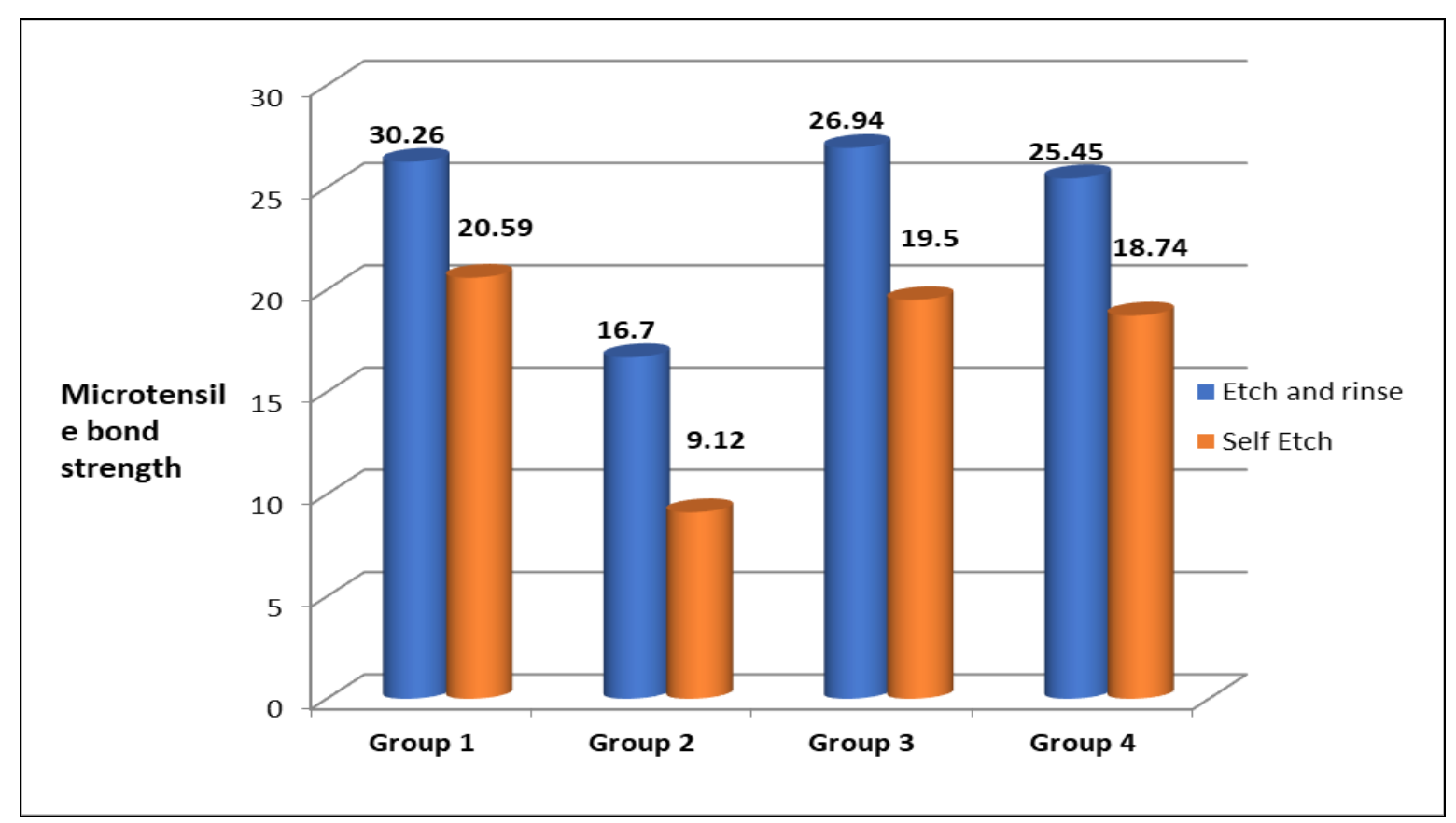

Fig 2: Intergroup comparison of the microtensile bond strength of bleached enamel to composite resin using two adhesive systems. 


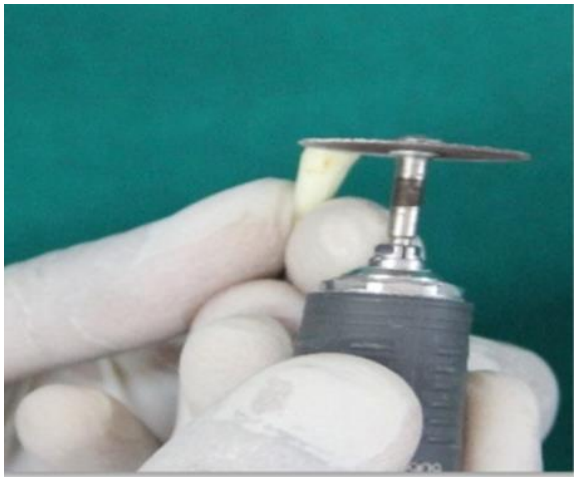

Fig 1: Decoronation of tooth

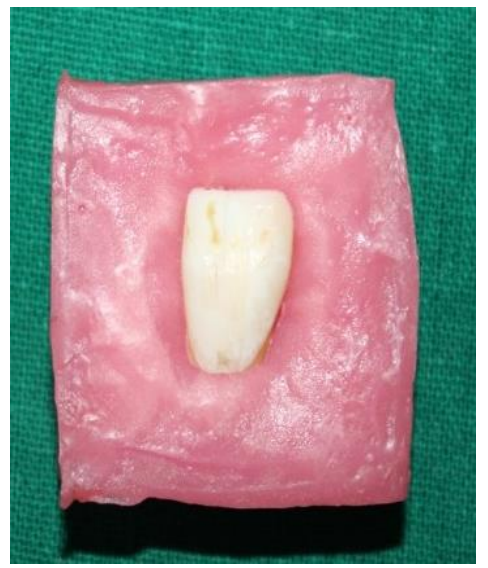

Fig 2: Tooth embedded in acrylic resin with buccal surface facing upwards

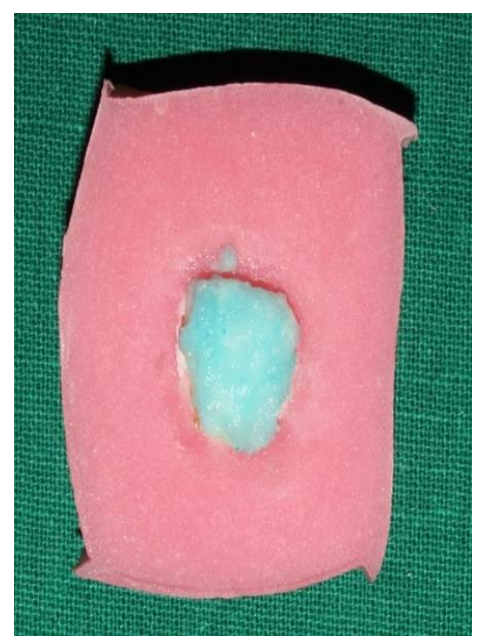

Fig 3: Bleaching with 35\% hydrogen peroxide gel

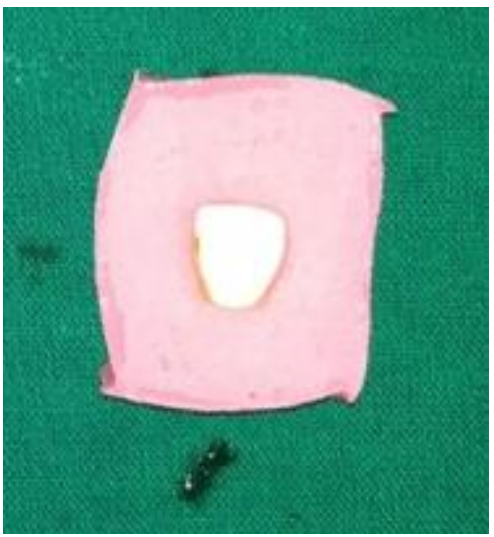

Fig 4: Application of $10 \%$ sodium ascorbate

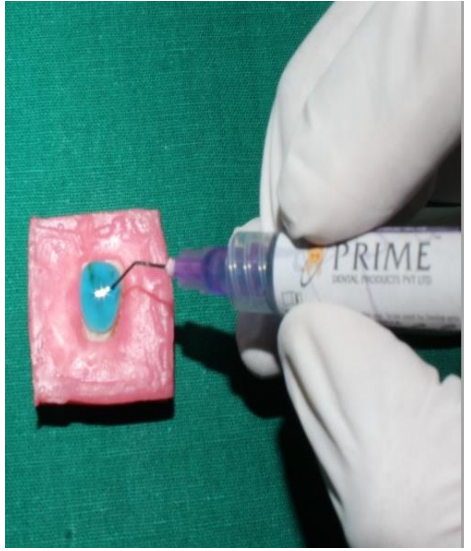

Fig 5: Post bleaching application of $37 \%$ phosphoric acid for total etch group

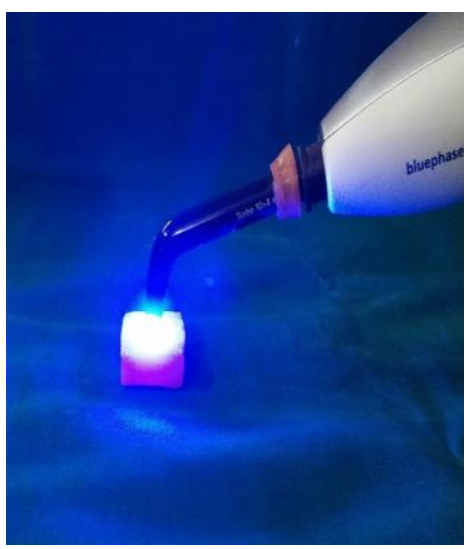

Fig 6: Application of bonding agent for total etch group

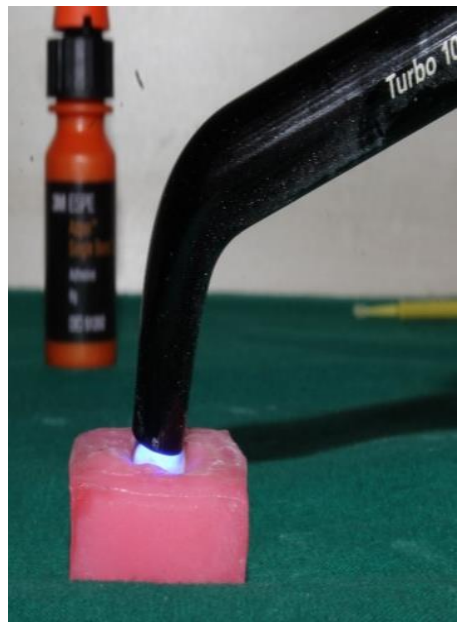

Fig 7: Application of only bonding agent for self-etch group

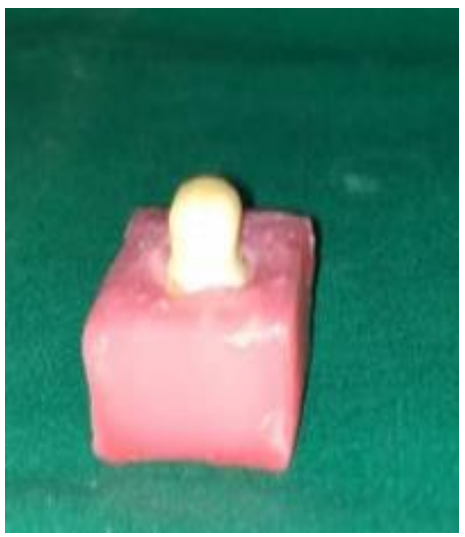

Fig 8: Incremental build up of composite resin 


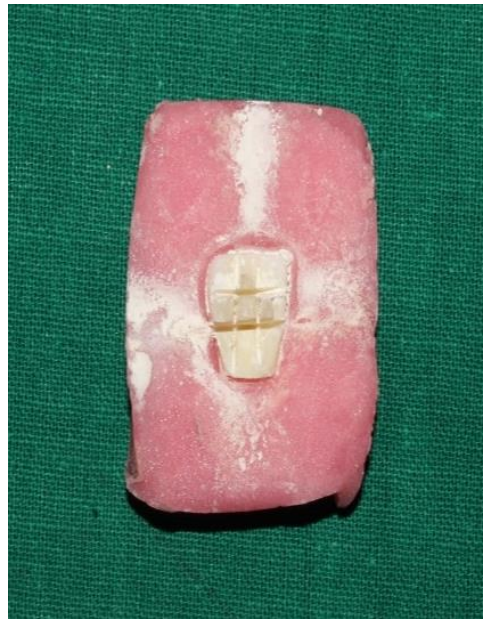

Fig 9: Specimens cut with diamond disk

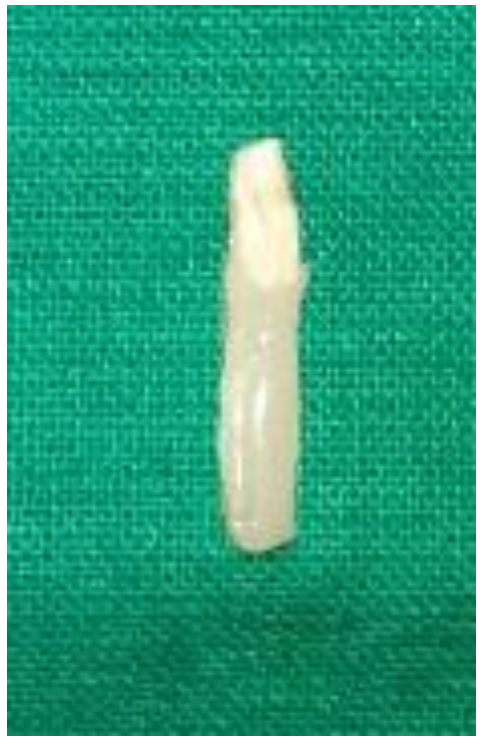

Fig 10: Prepared specimen

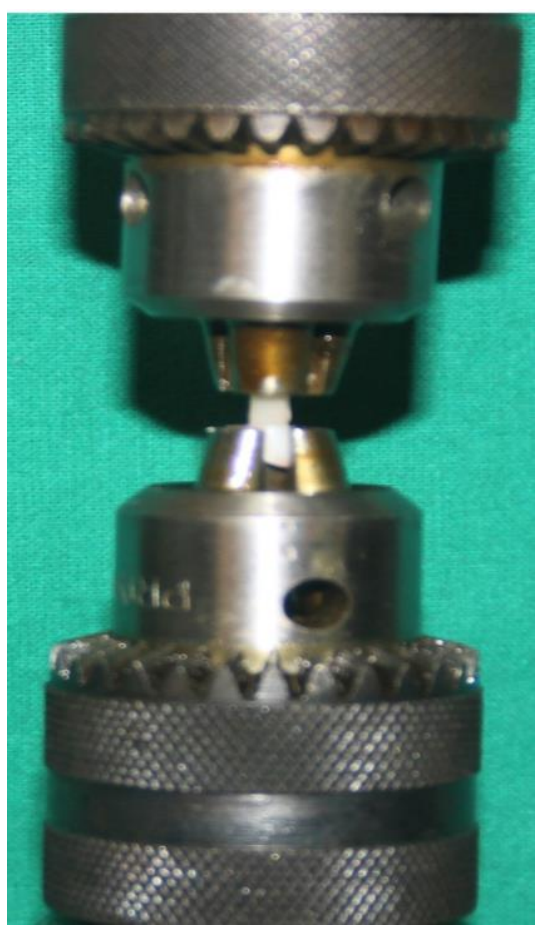

Fig 11: Specimen under microtensile bond strength testing

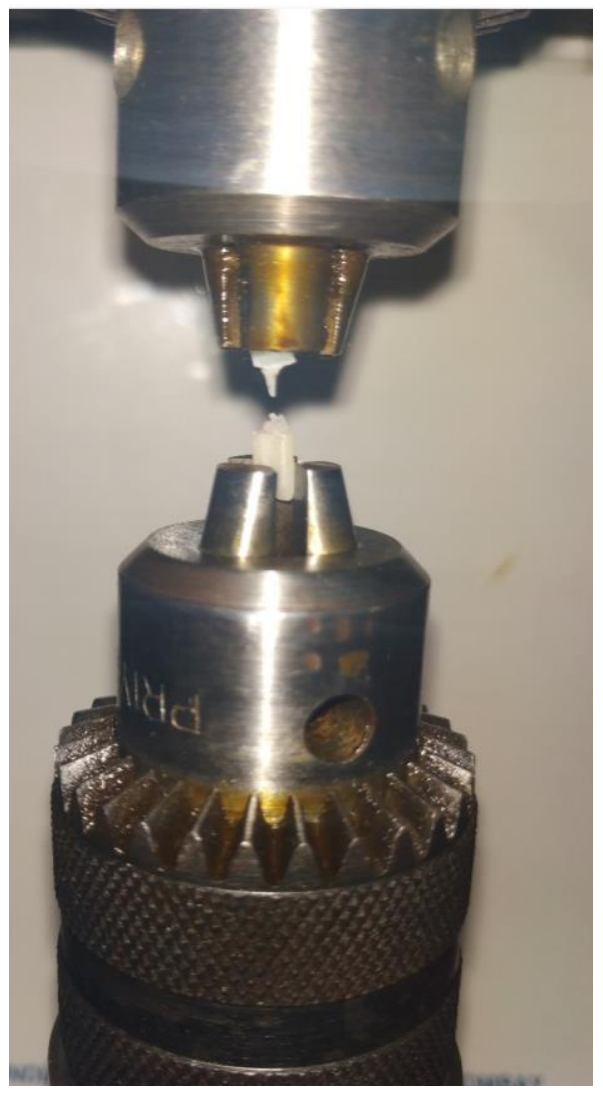

Fig 12: Debonding of the sample

\section{Conclusion}

- Original microtensile bond strength of tooth to composite resin was not achieved by any of the treatment protocol after bleaching.

- Application of $10 \%$ sodium ascorbate solution proves to be a promising material for reversing the action of bleaching agent. Therefore, antioxidant treatment can be considered a proper technique for enhancing the bond strength of bleached teeth.

- Different adhesive systems can affect the amount of bond strength after antioxidant treatments.

- Delaying the bonding process for at least one week after bleaching can result in almost the same bond strength as that achieved after antioxidant treatment.

\section{References}

1. Bhuvaneswaran M. Principles of smile design. Journal of Conservative Dentistry, 2010;13(4):225.

2. Anil M. Effect of $10 \%$ Sodium Ascorbate on Shear Bond Strength of Bleached Teeth - An in-vitro Study. Journal of Clinical and Diagnostic Research 2015.

3. Alqahtani M. Tooth-bleaching procedures and their controversial effects: A literature review. The Saudi Dental Journal 2014;26(2):33-46.

4. Plotino G, Buono L, Grande N, Pameijer C, Somma F. Nonvital Tooth Bleaching: A Review of the Literature and Clinical Procedures. Journal of Endodontics, 2008;34(4):394-407.

5. Dishman M, Covey D, Baughan L. The effects of peroxide bleaching on composite to enamel bond strength. Dental Materials 1994;10(1):33-3

6. May L, Salvia A, Souza R, Michida S, Valera M, Takahashi F et al. Effect of Sodium Ascorbate and the Time Lapse before Cementation after Internal Bleaching on Bond Strength between Dentin and Ceramic. Journal of Prosthodontics 2010;19(5):374-380.

7. Teixeira F, Teixeira E, Thompson J, Leinfelder K, Trope 
M. Dentinal Bonding Reaches the Root Canal System. Journal of Esthetic and Restorative Dentistry, 2004;16(6):348-354.

8. Türkün M, Kaya A. Effect of $10 \%$ sodium ascorbate on the shear bond strength of composite resin to bleached bovine enamel. Journal of Oral Rehabilitation, 2004;31(12):1184-1191.

9. Kimyai S, Valizadeh $H$. The Effect of Hydrogel and Solution of Sodium Ascorbate on Bond Strength in Bleached namel. Operative Dentistry 2006;31(4):496499.

10. Kimyai S, Oskoee S, Rafighi A, Valizadeh H, Ajami A, Helali Z. Comparison of the effect of hydrogel and solution forms of sodium ascorbate on orthodontic bracket-enamel shear bond strength immediately after bleaching: An in vitro study. Indian Journal of Dental Research 2010;21(1):54.

11. Lai SC, Tay FR, Cheung GS et al. Reversal of compromised bonding in bleached enamel. J Dent Res 2002;81:477-81.

12. Sano H, Chowdhury AF, Saikaew P, Matsumoto M, Hoshika S, Yamauti M. The microtensile bond strength test: Its historical background and application to bond testing. Japanese Dental Science Revie 2020;56(1):24-31.

13. Kihn PW, Barnes DM, Romberg E, Peterson K. A clinical evaluation of 10 percent vs. 15 percent carbamide peroxide tooth-whitening agents. The Journal of the American Dental Association 2000;131(10):1478-84.

14. Alencar MS, Bombonatti JF, Maenosono RM, Soares AF, Wang L, Mondelli RF. Effect of two antioxidants agents on microtensile bond strength to bleached enamel. Brazilian dental journal 2016;27(5):532-6.

15. Khoroushi M, Fardashtaki SR. Effect of light-activated bleaching on the microleakage of Class V tooth-colored restorations. Operative dentistry 2009;34(5):565-70.

16. Titley KC, Torneck CD, Smith DC, Chernecky R, Adibfar A. Scanning electron microscopy observations on the penetration and structure of resin tags in bleached and unbleached bovine enamel. Journal of endodontics. 1991;17(2):72-5.

17. Feiz A, Mosleh H, Nazeri R. Evaluating the effect of antioxidant agents on shear bond strength of toothcolored restorative materials after bleaching: a systematic review. Journal of the mechanical behavior of biomedical materials 2017;71:156-64.

18. Kalili T, Caputo AA, Mito R, Sperbeck G, Matyas J. In vitro toothbrush abrasion and bond strength of bleached enamel. Practical periodontics and aesthetic dentistry: PPAD 1991;3(5):22-4.

19. Barghi N, GODWIN JM. Reducing the adverse effect of bleaching on composite-enamel bond. Journal of Esthetic and Restorative Dentistry 1994;6(4):157-61.

20. Sung EC, Chan SM, Mito R, Caputo AA. Effect of carbamide peroxide bleaching on the shear bond strength of composite to dental bonding agent enhanced enamel. The Journal of prosthetic dentistry 1999;82(5):595-9.

21. Torres CRG, Koga AF, Borges AB. The effects of antioxidant agents as neutralizers of bleaching agents on enamel bond strength 2006;5:971-976.

22. Loretto SC, Braz R, Lyra AM, Lopes LM. Influence of photopolymerization light source on enamel shear bond strength after bleaching. Brazilian dental journal. 2004;15(2):133-7.

23. Cavalli V, Carvalho RM, Giannini M. Influence of carbamide peroxide-based bleaching agents on the bond strength of resin-enamel/dentin interfaces. Brazilian oral research 2005;19(1):23-9.

24. Van der Vyver PJ, Lewis SB, Marais JT. The effect of bleaching agent on composite/enamel bonding. The
Journal of the Dental Association of South Africa= Die Tydskrif van die Tandheelkundige Vereniging van SuidAfrika 1997;52(10):601-3.

25. Unlu N, Cobankara FK, Ozer F. Effect of elapsed time following bleaching on the shear bond strength of composite resin to enamel. Journal of Biomedical Materials Research Part B: Applied Biomaterials: An Official Journal of The Society for Biomaterials, The Japanese Society for Biomaterials, and The Australian Society for Biomaterials and the Korean Society for Biomaterials 2008;84(2):363-8.

26. Freire A, Durski MT, Ingberman M, Nakao LS, Souza EM, Vieira S. Assessing the use of 35 percent sodium ascorbate for removal of residual hydrogen peroxide after in-office tooth bleaching. The Journal of the American Dental Association 2011;142(7):836-41.

27. Kaya AD, Türkün M, Arici ME. Reversal of compromised bonding in bleached enamel using antioxidant gel. Operative dentistry 2008;33(4):441-7.

28. Lai SC, Mak YF, Cheung GS, Osorio R, Toledano M, Carvalho RM et al. Reversal of compromised bonding to oxidized etched dentin. Journal of Dental Research. 2001;80(10):1919-24.

29. Kimyai S, Oskoee SS, Rafighi A, Valizadeh H, Ajami AA, Helali ZN. Comparison of the effect of hydrogel and solution forms of sodium ascorbate on orthodontic bracket-enamel shear bond strength immediately after bleaching: an in vitro study. Indian Journal of Dental Research 2010;21(1):54.

30. Türkün M, Çelik EU, Kaya AD, Arıcı M. Can the hydrogel form of sodium ascorbate be used to reverse compromised bond strength after bleaching?. Journal of Adhesive Dentistry 2009;11(1).

31. Dabas D, Patil AC, Uppin VM. Evaluation of the effect of concentration and duration of application of sodium ascorbate hydrogel on the bond strength of composite resin to bleached enamel. Journal of conservative dentistry: JCD 2011;14(4):356.

32. Lima AF, Fonseca FM, Freitas MS, Palialol AR, Aguiar FH, Marchi GM. Effect of bleaching treatment and reduced application time of an antioxidant on bond strength to bleached enamel and subjacent dentin. Journal of Adhesive Dentistry 2011.

33. Thapa A, Vivekananda PA, Thomas MS. Evaluation and comparison of bond strength to $10 \%$ carbamide peroxide bleached enamel following the application of $10 \%$ and $25 \%$ sodium ascorbate and alpha-tocopherol solutions: An in vitro study. Journal of conservative dentistry: JCD. 2013;16(2):111.

34. Abraham S, Ghonmode WN, Saujanya KP, Jaju N, Tambe VH, Yawalikar PP. Effect of grape seed extracts on bond strength of bleached enamel using fifth and seventh generation bonding agents. Journal of international oral health: JIOH. 2013;5(6):101.

35. Ozoe R, Endo T, Abe R, Shinkai K, Katoh Y. Initial shear bond strength of orthodontic brackets bonded to bleached teeth with a self-etching adhesive system. Quintessence International 2012;43(5).

36. Yoon M, Burrow MF, Wong R, Parashos P. Effect of Sodium Ascorbate on Resin Bonding to Sodium Perborate-bleached Dentin. Operative dentistry 2014;39(1):98-106.

37. Harrison MS, Wang Y, Frick KJ, Moniz J, Walker MP. Effects of alpha-tocopherol antioxidant on dentincomposite microtensile bond strength after sodium perborate bleaching. Journal of endodontics 2019;45(8):1053-9. 